\title{
Transfers, returns to scale, tied aid and monopolistic competition
}

\author{
Steven Brakman ${ }^{a}$, Charles van Marrewijk ${ }^{\text {b,* }}$ \\ aniversity of Groningen, Groningen, Netherlands \\ ${ }^{\mathrm{b}}$ Erasmus University Rotterdam, Rotterdam, Netherlands
}

Received 15 November 1992; final version received 15 July 1994

\begin{abstract}
We examine transfers and tied aid in a model with increasing returns to scale and monopolistic competition. Transfers give rise to an additional (love of variety) welfare effect and affect the utility possibility locus. Generic tied aid may exacerbate or reverse these results. The popularity of aid tied to specific manufactured goods can be explained through rent-seeking behavior since such aid gives rise to profits in the donor country. These profits in turn largely repatriate the transfer such that donors can appear to be more generous than they really are.
\end{abstract}

Keywords: Tied aid; Monopolistic competition

JEL classification: $\mathrm{F} 0 ; \mathrm{F} 35 ; \mathrm{O} 1$

\section{Introduction}

There exists a substantial literature on the welfare effects of unilateral transfers (foreign aid) between countries. ${ }^{1}$ Recent attention has shifted to the analysis of

\footnotetext{
${ }^{*}$ Erasmus University Rotterdam, H8-13, Dep. of International Economics, P.O. Box 1738, 3000 DR Rotterdam, The Netherlands.

${ }^{1}$ See e.g. Ohyama (1974), Gale (1974), Chichilnisky (1980) and Bhagwati et al. (1983), Bhagwati et al. (1985). For an historical debate of the transfer problem see Chipman (1966), for a survey see Jones and Neary (1984).
} 
tied aid. ${ }^{2}$ All these studies, however, assume perfect competition, constant returns to scale and price taking behavior by the producers and consumers and therefore fail to take into account the developments in trade modeling for the past decade or so, emphasizing scale economies, imperfect competition and product differentiation. ${ }^{3}$ Traditional trade models cannot explain the empirical 'stylized facts' while the models incorporating the features mentioned above, developed e.g. by Ethier and Horn (1984) or Markusen (1986), are able to explain these empirical observations. ${ }^{4}$

This article analyzes the transfer problem in a model which, in its basic form, has become widely accepted in the trade literature in the last 10 odd years, incorporates the modern developments in international trade theory and by doing so embodies the 'stylized' facts mentioned above. For ease of exposition attention is restricted to a two-country model involving just the donor and the recipient of the transfer. Incorporation of more countries, however, is straightforward, see Brakman and van Marrewijk (1991b). Since differences in the demand structure of donor and recipient are the driving force behind any transfer effects (with the exception of the direct income effect), we focus our analysis on different spending behavior and different demand elasticities for donor and recipient. ${ }^{5}$

The model distinguishes between two types of commodities, a basic commodity (called food) produced under constant returns to scale and a large number of manufactures produced under increasing returns to scale in monopolistic competition. There is an externality in the model since consumers like an increase in the number of varieties of manufactures produced, but producers of these varieties do not take this into consideration. In equilibrium, therefore, not enough manufactures are produced and our analysis is about second-best welfare economics. In the absence of distortions lump-sum transfers only entail a movement along a given possibility locus, but with distortions there is a shift of the world utility possibility locus as well as a movement along it.

The tying of aid is modeled following Schweinberger's (1990) 'forced choice' approach. The donor gives a transfer to the recipient on the condition that it spends

\footnotetext{
${ }^{2}$ See e.g. Kemp and Kojima (1985a), Kemp and Kojima (1985b) and Kemp and Kojima (1987), Schweinberger (1990), Kemp and Shimomura (1991) and Jepma (1991).

${ }^{3}$ See e.g. Krugman (1979), Krugman (1990), Lancaster (1980), Helpman (1981) and Ethier (1982). Choi and Yu (1987) are somewhat of an exception as they analyze non-tied transfers under economies of scale in a two-good, two-country framework. The economies of scale however, are external to the firm, which therefore is still a pricetaker on the goods market.

${ }^{4}$ The 'stylized facts' are: (i) trade between DCs is usually intra-industry trade, while trade between DCs and LDCs is usually inter-industry trade, (ii) LDCs export a narrow range of primary products and depend for 'advanced' manufactured goods on DCs, while (iii) DCs export a wide range of different manufactured goods characterized by increasing returns to scale and can exercise some monopoly power. Clague (1991) tests a variant of the 'new' models for LDCs.

${ }^{5}$ Naturally, if demand is identical for donor and recipient transfers can still have real effects if aid is tied to a specific (group of) good(s).
} 
at least the amount of the transfer on the specified good or group of goods. If the recipient freely chooses to spend more on the good to which the transfer is tied, then the tying of aid is not an effectively binding restriction and the welfare effects are identical to those for non-tied aid. ${ }^{6}$

We show furthermore that the imposition of a 'fictitious' restriction (i.e. imposing a restriction that is already fulfilled of tying aid to a specific manufactured good) can have real effects. In contrast to existing models this can explain the popularity of tied aid because as a result profits are made (which makes lobbying interesting) and the transfer itself is largely repatriated (hence one can appear to be more generous then one really is).

\section{The model}

The basic model, extensively documented by Tirole (1988), is by now wellknown in international economic theory and has been developed, for example, by Dixit and Norman (1980) and Krugman (1990) to explain intra-industry trade. There will be a 'developed' country, A, and a 'less developed' country, B. Country A (the donor) gives a transfer (aid) to country B (the recipient). The transfer can be in the form of tied aid or non-tied aid. There are no tariffs, quotas or other barriers to trade.

On the demand side two types of commodities are distinguished: (i) a standard basic commodity (or commodity bundle) which will be called food $(F)$ and serves as numéraire, and (ii) a range of differentiated manufactured goods. The manufactured goods will be indexed $X_{i}, i=1, \ldots, n$. From the consumers' point of view the manufactured goods are close but imperfect substitutes. Preferences are of the Spence-Dixit-Stiglitz type. ${ }^{7}$

$$
U^{k}=\left[\sum_{i=1}^{n}\left(X_{i}^{k}\right)^{\beta_{k}}\right]^{\alpha_{k} / \beta_{k}}\left(F^{k}\right)^{1-\alpha_{k}} ; \quad k=A, B,
$$

with $0<\alpha_{k}<1$ and $0<\beta_{k}<1$. Naturally, $X_{i}^{k}$ is the amount of manufactured good $i$ which is consumed by country $k=\mathrm{A}$, B. Hence $\beta_{k}$ is a monotone

\footnotetext{
${ }^{6}$ Should the recipient, for example, spend half its income on food consumption and aid is tied to food, then the tying restriction becomes binding only when the transfer exceeds the recipient's productive income! Presumably, therefore, most generic tied aid, such as aid tied to the consumption of food or manufactures in general, is not effectively binding and therefore does not require a separate analysis despite the fact that aid can represent a substantial part (e.g. 77 percent of GNP recently for Mozambique) of a recipient's income. Naturally, non-generic tied aid, such as aid tied to a particular manufactured good, will be more easily binding.

${ }^{7}$ This is an application of the Leontief condition for aggregation, see e.g. van Daal and Merkies (1984). The utility function of the literature mentioned in the introduction is usually more general in the sense that it only assumes quasi-concavity.
} 
transformation of the elasticity of substitution for manufactured goods $\left(\beta_{k}=1-\right.$ $1 / \epsilon_{k}$ if $\epsilon_{k}$ is the elasticity of substitution for manufactured goods in country $k$ ) and $\alpha_{k}$ represents the share of income spent on the consumption of manufactured goods. If the number of varieties is large, as we will assume, the Marshallian price elasticity of demand can be approximated by the elasticity of substitution for manufactured goods, see Horn (1984) for this approximation and Dixit and Stiglitz (1993) for a recent discussion. We first develop the model under assumption 1 below and investigate differences in spending pattern in rich and poor countries. The consequences of different demand elasticities will be discussed briefly in Section 6 .

Assumption 1. The elasticity of demand is the same in both countries, i.e. $\beta_{\mathrm{A}}=\beta_{\mathrm{B}}=\beta$, while the developed country spends a larger share of income on manufactured goods, i.e. $\alpha_{\mathrm{A}}>\alpha_{\mathrm{B}}$.

The basic good is produced in both countries using constant returns to scale technology. All factor markets are perfectly competitive. The production of manufactured goods requires special techniques and skilled labor and can only take place in the developed country A. As country B cannot produce manufactured goods it will only produce food at the amount $I_{\mathrm{B}}$, which also represents its income because food is the numéraire. The production of manufactured goods is characterized by (internal) increasing returns to scale, where the non convexity only occurs on the corner. Hence production of each variety within the manufacturing industry sector will be undertaken by just one firm. It is most convenient to model the production process in two stages. ${ }^{8}$ First, standard factors of production (capital and labor, say) are used to produce food and an intermediate good, $M$, under constant returns. This first step then leads to a standard production possibility curve $G(M)$, with negative first and second derivative. ${ }^{9}$ The tangent to the production possibility curve equals minus the price $(r)$ of intermediates, $r=$ $-G^{\prime}(M)$. Second, the intermediate good is used to produce manufactured goods, each variety of which uses the same production technique. Internal increasing returns to scale are represented by the real fixed costs $a$ (in terms of intermediates) and the (constant) marginal costs $b$ (also in terms of intermediates). In equilibrium

\footnotetext{
${ }^{8}$ The results derived below, however, also hold for an appropriately defined one-stage modeling procedure that uses only one factor of production, labor say. The advantages of this two-stage approach also used by Ethier and Horn (1984) is that different inputs, like labor, land and capital, can lead to the strictly concave production possibility curve above and that there is a clear choice in inputs devoted to the constant returns to scale part of the economy (food) on the one hand and the increasing returns to scale part of the economy (manufactures) on the other hand.

${ }^{9}$ Hence $G(M)$ gives the amount of food country A can produce if it produces $M$ of the intermediate good. Obviously, there is an upper bound, $\bar{M}$ say, to the amount of intermediates country A can produce which is dictated by the available amount of factors of production and technology.
} 
all firms will produce the same output. Accordingly we can write this as ( $n$ equals the number of firms)

$$
M=n(a+b X) \text {. }
$$

Furthermore, we have from the conditions of profit maximization in each industry (marginal cost equals marginal revenue):

$$
p \beta=r b \text {. }
$$

From the fact that total profits in each industry are zero (otherwise new firms would enter the market) we have $\mathrm{i}^{10}$

$$
p X=r M / n \text {. }
$$

Using Eqs. (2)-(4) we can derive the output of each firm in an industry:

$$
X=a \beta /[b(1-\beta)] \text {. }
$$

Applying Eqs. (2) and (5) gives the number of varieties as a function of the production of intermediates.

$$
n=[(1-\beta) / a] M
$$

The demand functions for manufacturing products and food, which can be derived from utility maximization, are

$$
\begin{aligned}
& X_{i}^{k}=\alpha_{k} I_{k} / p n, \\
& F_{k}=\left(1-\alpha_{k}\right) I_{k} .
\end{aligned}
$$

Market clearing conditions and country A's income are: ${ }^{11}$

$$
\begin{aligned}
& X=\left[\alpha_{\mathrm{A}} I_{\mathrm{A}}+\alpha_{\mathrm{B}} I_{\mathrm{B}}\right] / p n, \\
& G(M)+I_{\mathrm{B}}=\left(1-\alpha_{\mathrm{A}}\right) I_{\mathrm{A}}+\left(1-\alpha_{\mathrm{B}}\right) I_{\mathrm{B}}, \\
& I_{\mathrm{A}}=G(M)+r M .
\end{aligned}
$$

The model is determined (by Walras' law) by the equilibrium condition for the food sector and the production possibility curve. It is easy to incorporate transfers into the model, simply by subtracting $T$ from A's income and adding it to B's income. ${ }^{12}$ The model, now incorporating transfers, can be reduced to the following equation (use $r=-G^{\prime}(M)$ and Eq. (11)):

$$
\begin{aligned}
L(M) & \equiv-\left(1-\alpha_{\mathrm{A}}\right) G^{\prime}(M) M=\alpha_{\mathrm{A}} G(M)+\left\{\alpha_{\mathrm{B}} I_{\mathrm{B}}-\left(\alpha_{\mathrm{A}}-\alpha_{\mathrm{B}}\right) T\right\} \\
& \equiv R_{\mathrm{u}}(M ; T) .
\end{aligned}
$$

The functions $L(M)$ and $R_{\mathrm{u}}(M ; T)$ are defined for convenience.

\footnotetext{
${ }^{10}$ Note that, as usual, we abstract from the integer problem here.

${ }^{11}$ Note that in equilibrium there are no profits in the manufactured goods sector in country $\mathrm{A}$, hence $p n X=r M$ and $I_{\mathrm{A}}=G(M)+r M$.

${ }^{12}$ The transfer could be made endogenous by relating it to either the donor's or recipient's expenditure or revenue level. Brakman and van Marrewijk (1991a), however, show that this has no material consequences for the analysis in the sequel.
} 
As we are interested in the welfare consequences of transfers we also state the indirect utility function which is given by ( $I_{k}^{\mathrm{d}}=k$ 's disposable income, $\left.k=\mathrm{A}, \mathrm{B}\right)$

$$
\vartheta_{k}=K_{k}\left(p^{-\alpha_{k}}\right)\left(n^{\phi_{k}}\right) I_{k}^{\mathrm{d}} \quad \text { for } k=\mathrm{A}, \mathrm{B},
$$

with

$$
K_{k}=\left(\alpha_{k}\right)^{\alpha_{k}}\left(1-\alpha_{k}\right)^{\left(1-\alpha_{k}\right)} ; \quad \phi_{k}=\alpha_{k}(1-\beta) / \beta .
$$

\section{Non-tied aid}

First, we discuss non-tied aid. A priori one might expect this form of aid to be most beneficial for the recipient. Given the initial size of the transfer the initial equilibrium quantity of intermediates produced is determined by the unique point of intersection of the (upward-sloping) $L$-curve and the (downward-sloping) $R_{\mathrm{u}}$-curve (where the $\mathrm{u}$ indicates untied aid) as defined in Eq. (12) above. ${ }^{13}$ An increase in non-tied aid does not affect the $L$-curve, but shifts the $R_{\mathrm{u}}$-curve down by the amount $\left(\alpha_{\mathrm{A}}-\alpha_{\mathrm{B}}\right)$ times the change in the transfer. This reduces the equilibrium production of intermediates, which in turn reduces the number of varieties produced, etc. These qualitative conclusions hold for discrete changes in the size of the transfer. The change in the production level of intermediates relative to the change in the transfer depends also on the (change in) the slopes of the $L$-curve and the $R_{\mathrm{u}}$-curve. To gauge the size of this and related relative changes we use (local) calculus techniques. Differentiating (12) leads to

$$
\hat{M} / \hat{T}=-\left(\alpha_{\mathrm{A}}-\alpha_{\mathrm{B}}\right) /\left[1+\left(1-\alpha_{\mathrm{A}}\right) \sigma\right]<0,
$$

with

$$
\hat{T} \equiv \mathrm{d} T / r M ; \quad \sigma \equiv M G^{\prime \prime} / G^{\prime} .
$$

Hence $\hat{T}$ denotes the change of the transfer in relation to total world spending on manufactured goods and $\sigma$ is the elasticity of substitution in the supply of intermediates. All other ' ${ }^{\prime \prime}$ ' signs refer to relative changes, i.e. $\hat{M}=\mathrm{d} M / M$, etc. Since $\hat{r}=\sigma \hat{M}, \hat{p}=\hat{r}$ (Eq. 3) and $\hat{n}=\hat{M}$ (Eq. 6) we get

Proposition 1. Under Assumption 1 a non-tied transfer induces:

$i$ a price decrease for all manufactured goods,

ii a decrease in the number of varieties in the manufactured goods industry,

iii an increase in the production and consumption of food.

\footnotetext{
${ }^{13}$ Examples of these curves are given in Figs. 1 and 2 below. Note that the $R$-curve is concave and $L(0)=0$.
} 
Proposition 1 can be given the usual interpretation. If country A transfers income to country $B$ and country B spends a smaller portion out of this income on manufactures, then the price of manufactures falls, which in this setting causes a concomitant fall in the number of varieties.

The relative change in indirect utility can be calculated from Eq. (13). Let $\omega_{k}$ be the share of the domestically produced value of manufactured products in disposable income, i.e. $\omega_{\mathrm{A}}=r M / I_{\mathrm{A}}^{\mathrm{d}}$ and $\omega_{\mathrm{B}}=0$. Since country $\mathrm{A}(\mathrm{B})$ is a net exporter (importer) of manufactured goods we have $\omega_{\mathrm{A}}-\alpha_{\mathrm{A}}>0\left(\omega_{\mathrm{B}}-\alpha_{\mathrm{B}}<0\right)$. Let $\eta_{k}$ be country $k$ 's disposable income over the world value of manufactured products, i.e. $\eta_{\mathrm{A}}=I_{\mathrm{A}}^{\mathrm{d}} / r M\left(=1 / \omega_{\mathrm{A}}\right.$ in this two-country world $)$ and $\eta_{\mathrm{B}}=I_{\mathrm{B}}^{\mathrm{d}} / r M$ $\left(\neq 1 / \omega_{\mathrm{B}}\right)$. Then we get $\hat{\mathrm{I}}_{\mathrm{A}}^{\mathrm{d}}=\omega_{\mathrm{A}} \hat{r}-\hat{T}\left(1 / \eta_{\mathrm{A}}\right)$ and $\hat{\mathrm{I}}_{\mathrm{B}}^{\mathrm{d}}=\hat{T}\left(1 / \eta_{\mathrm{B}}\right)$ and welfare effects

$$
\begin{aligned}
& \hat{\vartheta}_{\mathrm{A}}=\left(\omega_{\mathrm{A}}-\alpha_{\mathrm{A}}\right) \hat{p}+\phi_{\mathrm{A}} \hat{n}-\left(1 / \eta_{\mathrm{A}}\right) \hat{T}<0, \\
& \hat{\vartheta}_{\mathrm{B}}=\left(\omega_{\mathrm{B}}-\alpha_{\mathrm{B}}\right) \hat{p}+\phi_{\mathrm{B}} \hat{n}+\left(1 / \eta_{\mathrm{B}}\right) \hat{T}
\end{aligned}
$$

Note that, in contrast to traditional transfer models, the welfare effects consist of three rather than two components. There is not only the terms-of-trade effect and the income effect, but also a 'love-of-variety' effect. The latter is the positive externality associated with the production of manufactured goods (not taken into consideration by the producers). Hence in (the non-Pareto-optimal) equilibrium there is an under-production of the number of manufactured goods. This underproduction will be exacerbated by an increase in the transfer as it further reduces the number of varieties produced. Note that this externality, the love-of-variety effect, is smaller the easier it is to substitute one manufactured good for another (if $\beta$ increases and therefore $\phi_{\mathrm{A}}$ and $\phi_{\mathrm{B}}$ fall). ${ }^{14}$

The donor's welfare is reduced for three reasons: (i) there is a negative terms-of-trade effect $\left[\left(\omega_{\mathrm{A}}-\alpha_{\mathrm{A}}\right) \hat{p}<0\right]$ because the price of manufactured goods falls and the donor is a net exporter of these goods, (ii) there is a negative variety effect because the fall in the price of manufactured goods induces a reduction in the number of varieties produced $\left(\phi_{\mathrm{A}} \hat{n}<0\right)$ and (iii) there is a negative income effect due to the transfer itself $\left[-\left(1 / \eta_{\mathrm{A}}\right) \hat{T}<0\right] .^{15}$

\footnotetext{
${ }^{14}$ In an earlier version we erroneously wrote that "this effect disappears if manufactured goods become perfect substitutes". However, the distortion due to imperfect competition does not quite disappear if $\beta$ approaches one (and therefore both $\phi_{\mathrm{A}}$ and $\phi_{\mathrm{B}}$ approach zero) because then the number of varieties becomes small and we cannot "abstract from the integer problem" (see footnote 10) anymore as the market will move into a form of oligopoly or monopoly. Addressing this issue would require the modeling of varieties as a continuum of goods. We are very grateful to an anonymous referee for pointing this out.

${ }^{15}$ It should be clear that if we extend the model to three or more countries those countries not directly involved in the transfer will only face the terms-of-trade effect and the love-of-variety effect, see Brakman and van Marrewijk (1991b).
} 
The recipient is faced with two positive effects and one negative effect. As the recipient is a net exporter of food the terms-of-trade effect is positive, as is, of course, its direct income effect. In fact, the latter effect will usually be quite large as the recipient's income tends to be small compared to the world expenditures on manufactured goods. The love-of-variety effect is negative, however, as the number of varieties declines. Therefore the net welfare effect for the recipient is inconclusive because the love-of-variety effect may potentially dominate both the terms-of-trade effect and the direct income effect. A sufficient condition for $\vartheta_{\mathrm{B}}$ to be positive is $(\epsilon-1) \sigma>1$, with $\epsilon=1 /(1-\beta)$ representing the elasticity of demand for a particular product in the manufacturing sector. ${ }^{16}$ Therefore the recipient's welfare improves if the product of demand and supply elasticity is sufficiently high. Recent empirical work in a similar framework by Gasiorek et al. (1991) reports very large values for the elasticity of demand, consistent with the work by Abraham (1991), ranging from 5.8 to 35. If we take $\epsilon$ close to 6 , the lowest estimate of Gasiorek et al., then an elasticity of supply of intermediates exceeding 0.2 would already be sufficient to guarantee that the recipient gains from the transfer. This condition will appear frequently throughout the rest of the paper, so we will give it a name.

Elasticity condition. We say the elasticity condition holds iff $(\epsilon-1) \sigma>1$, i.e. iff the demand for manufactured goods and the supply of intermediates is sufficiently elastic, which is equivalent to saying that the terms-of-trade effect dominates the love-of-variety effect.

This leads us to the following proposition.

Proposition 2. Under Assumption 1 the welfare effects of non-tied aid are always negative for the donor. The elasticity condition is sufficient to ensure that the recipient gains from non-tied aid.

\section{Tied aid}

This section discusses, in turn, two forms of generic tied aid: aid tied to food ('humanitarian' aid) and aid tied to manufactured goods in general.

\footnotetext{
${ }^{16}$ This condition is derived by combining the first two terms on the right-hand side of Eq. (16).
} 


\subsection{Aid tied to food}

First, we look at 'humanitarian' aid, i.e. aid tied to the consumption of food. The recipient maximizes Eq. (1) subject to the two restrictions

$$
\begin{aligned}
& \sum_{i=1}^{n} p X_{i}^{\mathrm{B}}+F^{\mathrm{B}} \leq I_{\mathrm{B}}+T, \\
& F^{\mathrm{B}} \geq T,
\end{aligned}
$$

where the first restriction is the budget constraint and the second restriction is the tying-of-aid constraint, representing the donor's condition that the recipient should spend at least the amount of the transfer on food consumption. Obviously, if the transfer is relatively small the recipient will voluntarily choose to spend more on food than the size of the transfer and the second restriction, Eq. (18), is not binding. As a result the same demand relations as before are operative, i.e. Eqs. (7) and (8). Consequently, within a certain range of transfers the tying-of-aid restriction is said to be not effective and within this range the effects of tied aid on welfare, prices, the number of varieties, etc. are the same as those for non-tied aid analyzed in the previous section. The analysis of tied aid becomes interesting if the tying-of-aid restriction is effective and the second restriction is binding. In that case the following demand relations hold:

$$
\begin{aligned}
X_{i}^{\mathrm{B}} & =I_{\mathrm{B}} / p n \quad i=1, \ldots, n, \\
F^{\mathrm{B}} & =T,
\end{aligned}
$$

which leads to the indirect utility function

$$
\vartheta_{\mathrm{B}}=\left(p^{-\alpha_{\mathrm{B}}}\right)\left(n^{\phi_{\mathrm{B}}}\right)\left(I_{\mathrm{B}}^{\alpha_{\mathrm{B}}}\right) T^{\left(1-\alpha_{\mathrm{B}}\right)} \text {. }
$$

The food market equilibrium becomes ${ }^{17}$

$$
G(M)+I_{\mathrm{B}}=\left(1-\alpha_{\mathrm{A}}\right)\left(I_{\mathrm{A}}-T\right)+T .
$$

From which the equilibrium production level of intermediates (using $r=$ $-G^{\prime}(M)$ and Eq. (11)) can be determined as follows:

$$
L(M)=\alpha_{\mathrm{A}} G(M)+\left\{I_{\mathrm{B}}-\alpha_{\mathrm{A}} T\right\} \equiv R_{\mathrm{tf}}(M ; T) .
$$

Equilibrium conditions (12) (for non-tied aid) and (12') (for aid tied to food) differ only in the term appearing in braces in the $R$-function. The discussion above is illustrated in Fig. 1. Suppose the initial equilibrium is at point $E_{0}$ with the initial transfer $T_{0}$ (which could be zero). An increase of the transfer from $T_{0}$ to $T_{1}$ shifts the $R$-curve down to $R_{\mathrm{u}}\left(M ; T_{1}\right)$ if aid is non-tied and results in equilibrium $E_{1}$, as analyzed in Section 3. Now note that an increase in the transfer from $T_{0}$ to $T_{1}$ if

\footnotetext{
${ }^{17}$ Note, that country B's preferences do not play a role in determining the terms of trade, but country B's technology does, see Schweinberger (1990).
} 


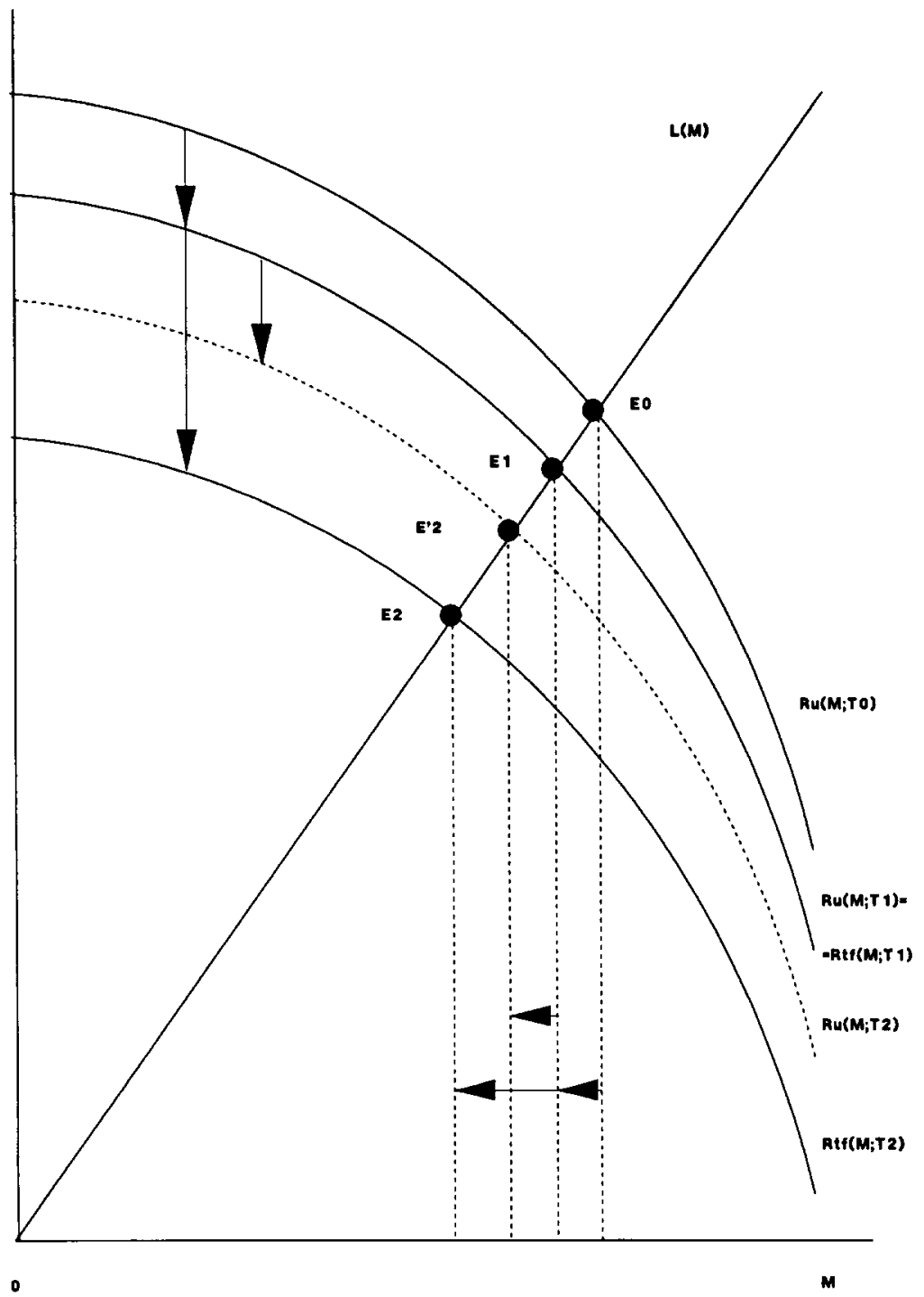

Fig. 1. The magnification effect of aid tied to food.

aid is tied to food but the tying restriction (18) is not effective also results in a downward shift of the $R$-curve to $R_{\mathrm{tf}}\left(M ; T_{1}\right)=R_{\mathrm{u}}\left(M ; T_{1}\right)$ and therefore also results in equilibrium $E_{1}$. Suppose that at $T_{1}$ the tying-to-food restriction (18) becomes just binding, i.e. $\left(1-\alpha_{\mathrm{B}}\right)\left(I_{\mathrm{B}}+T_{1}\right)=T_{1}$. A further increase of the transfer from $T_{1}$ to $T_{2}$ results in a further downward shift of the $R$-curve to $R_{\mathrm{u}}\left(M ; T_{2}\right)$ and equilibrium $E_{2}^{\prime}$ if aid is non-tied, but to a larger downward shift to 
$R_{\mathrm{tf}}\left(M ; T_{2}\right)<R_{\mathrm{u}}\left(M ; T_{2}\right)$ and equilibrium $E_{2}$ if aid is tied to food. Therefore we can conclude that, independently of the size of the transfer, aid tied to food leads to larger decreases in the price of manufactures, the number of varieties produced, etc. than non-tied aid provided the tying restriction (18) is effective. To put it differently, tying aid to food results in a 'magnification effect'.

Fig. 1 also clarifies another important aspect of tied aid. If we want to gauge the impact of aid tied to food instead of non-tied aid by comparing the size of various relative changes using calculus techniques, as we did in the previous section, we can do that usefully only at one point. We noted above that if the transfer is small (the tying-of-aid restriction is not effective) there is no difference between the effects of the two types of aid. If the transfer is large (the tying-of-aid restriction is effective), however, there is a difference. Suppose that we compare the effect of a small change in the transfer if aid is tied relative to untied aid starting from an initially large transfer like $T_{2}$ in Fig. 1 . This would be like comparing apples and oranges since we would be comparing changes at two different initial equilibria, $E_{2}$ and $E_{2}^{\prime}$ respectively, which affects, in particular, the elasticity of substitution in the supply of intermediates $\sigma$. Therefore, the initial transfer must be large enough such that there is a difference between tied aid and non-tied aid, whereas the transfer must be small enough in order to evaluate both at the same initial equilibrium point. The only initial transfer that satisfies both these criteria is transfer $T_{1}$ in Fig. 1 in which the tying-of-aid restriction (18) is just binding. Evaluation at that point ( $E_{1}$ in Fig. 1) also implies that Eq. (16) still holds (see the appendix). A further advantage of this approach is that the modelling of tied aid can then also be given Professor Kemp's interpretation of marginal tying, see Schweinberger (1990), since the outcome of the two approaches then coincide. Professor Kemp argues that the relevant constraint that might be imposed by the donor country is that additional food consumption (if aid is tied to food) as a consequence of an increase in the transfer must be at least as great as the increase in the transfer. ${ }^{18}$ Differentiation leads to ${ }^{19}$

$$
\left.\hat{r}\right|_{\mathrm{tf}}=\left.\hat{p}\right|_{\mathrm{tf}}=\left.\sigma \hat{n}\right|_{\mathrm{tf}}=\left.\sigma \hat{M}\right|_{\mathrm{tf}}=\left[\alpha_{\mathrm{A}} /\left(\alpha_{\mathrm{A}}-\alpha_{\mathrm{B}}\right)\right] \hat{r}<\hat{r}<0 .
$$

From this equation and the above discussion it is clear that the price and variety changes are larger (in absolute value) if aid is tied to food instead of non-tied. More precisely, these changes are $\alpha_{\mathrm{A}} /\left(\alpha_{\mathrm{A}}-\alpha_{\mathrm{B}}\right)>1$ times as large. This is easy to understand as the recipient is forced, through the tying of aid, to spend the

\footnotetext{
${ }^{18}$ The disadvantage of this interpretation is that it requires the introduction of a separate entity, the recipient's government, to receive the transfer, spent it as specified and distribute it to the private sector, as noted by Kemp and Kojima (1985a). Furthermore, the private sector is not supposed to take this into consideration in their own demand functions. Should these conditions fail then marginal tying coincides with untied aid unless the transfer is 'large'.

${ }^{19}$ The $\left.\right|_{\text {tf }}$ sign indicates that aid is tied to food.
} 
entire increase of the transfer exclusively on food consumption, rather than just the fraction $\left(1-\alpha_{\mathrm{B}}\right)$. The welfare changes are given by

$$
\begin{aligned}
& \left.\hat{\vartheta}_{\mathrm{A}}\right|_{\mathrm{tf}}=\left.\left(\omega_{\mathrm{A}}-\alpha_{\mathrm{A}}\right) \hat{p}\right|_{\mathrm{tf}}+\left.\phi_{\mathrm{A}} \hat{n}\right|_{\mathrm{tf}}-\left(1 / \eta_{\mathrm{A}}\right) \hat{T}<\hat{\vartheta}_{\mathrm{A}}<0, \\
& \left.\hat{\vartheta}_{\mathrm{B}}\right|_{\mathrm{tf}}=\left.\left(\omega_{\mathrm{B}}-\alpha_{\mathrm{B}}\right) \hat{p}\right|_{\mathrm{tf}}+\left.\phi_{\mathrm{B}} \hat{n}\right|_{\mathrm{tf}}+\left(1 / \eta_{\mathrm{B}}\right) \hat{T} .
\end{aligned}
$$

Hence welfare for the donor decreases more due to a larger terms-of- trade effect and a larger love-of-variety effect. The recipient of the transfer has a larger welfare gain due to the tying of aid to food, which forces it to use its monopoly power, relative to non-tied aid if and only if the elasticity condition holds, i.e. if and only if the terms-of-trade (monopoly) effect dominates the love-of-variety effect. One could therefore say that humanitarian aid is truly humanitarian if and only if the elasticity condition holds.

Proposition 3. Under Assumption 1 aid tied to food compared to non-tied aid causes

i a larger welfare decrease for the donor,

ii larger decreases in the price and number of manufactured goods,

iii a larger welfare gain for the recipient iff the elasticity condition holds.

\subsection{Aid tied to manufactures in general}

Sometimes, aid is not tied to a specific good (as discussed in Section 5), but the tying is 'coordinated' between donors to manufactures in general (see for examples of multi-country tying Jepma, 1991). It should come as no surprise that this case represents the mirror image of aid tied to food. The tying-of-aid constraint becomes

$$
\sum_{i=1}^{n} p X_{i}^{\mathbf{B}}>T .
$$

If this constraint is not effective, i.e. if the transfer is small, then generic tying of aid to manufactures has the same implications as non-tied aid because restriction (26) is not binding. If the transfer is large enough, i.e. if restriction (26) is binding, the demand relations are

$$
\begin{aligned}
& X_{i}^{\mathrm{B}}=T / p N, \\
& F^{\mathbf{B}}=I_{\mathrm{B}} .
\end{aligned}
$$

And the market clearing condition for food becomes ${ }^{20}$

$$
G(M)+I_{\mathrm{B}}=\left(1-\alpha_{\mathrm{A}}\right)\left(I_{\mathrm{A}}-T\right)+I_{\mathrm{B}},
$$

\footnotetext{
${ }^{20}$ Note again that the terms of trade can be determined without reference to the recipient's preference or technology if aid is tied to the donor's export good, see also Schweinberger (1990).
} 


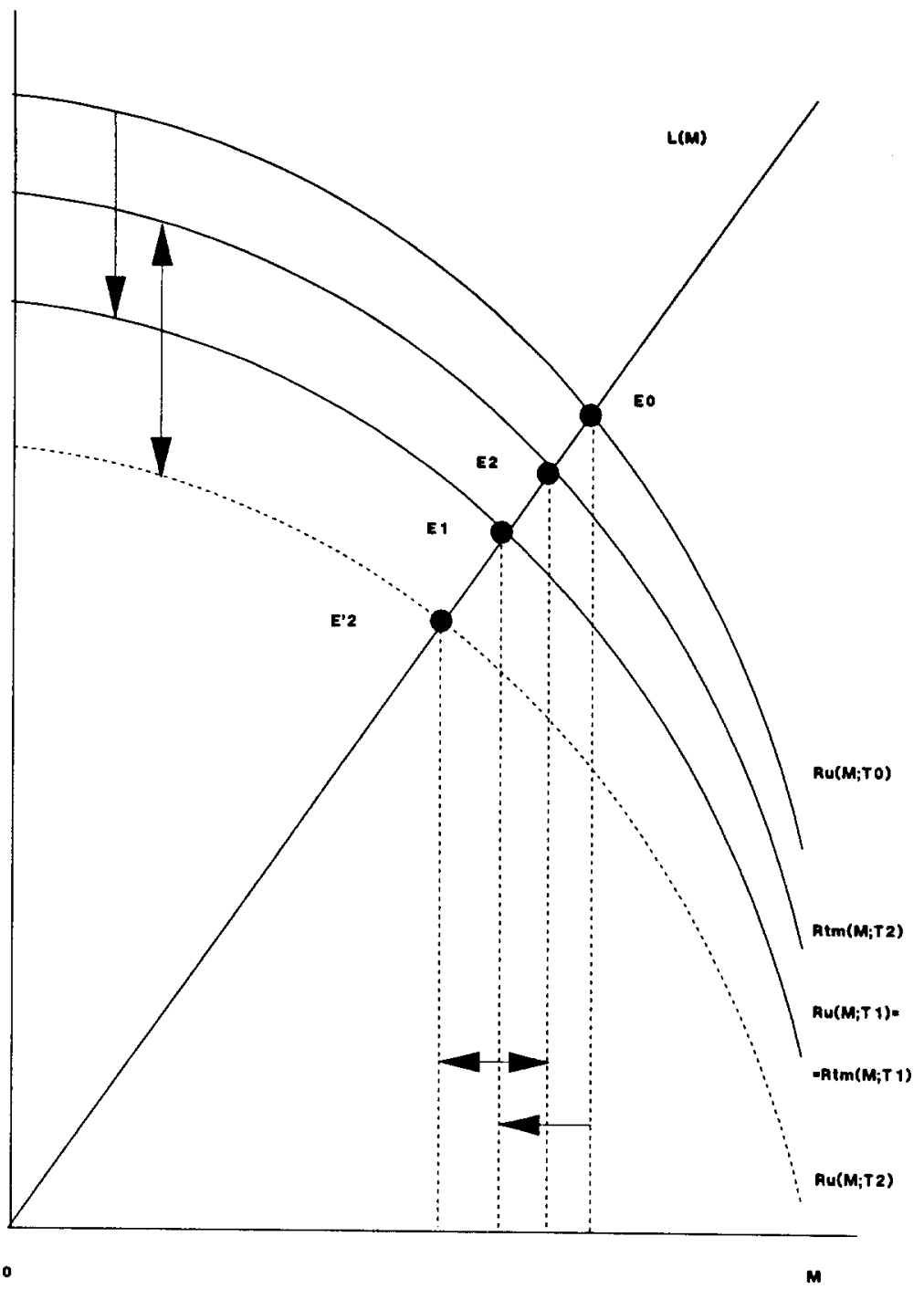

Fig. 2. The reversal effect of aid tied to manufactures in general.

from which the equilibrium production level of intermediates (using $r=-G^{\prime}(M)$ and Eq. (11)) can be determined as follows:

$$
L(M)=\alpha_{\mathrm{A}} G(M)+\left\{\left(1-\alpha_{\mathrm{A}}\right) T\right\} \equiv R_{\mathrm{tm}}(M ; T) .
$$

Equilibrium conditions (12) (for non-tied aid) and (12") (for aid tied to manufactures in general) also differ only in the term appearing in braces in the $R$-function. The situation is illustrated in Fig. 2. Starting from the initial equilibrium at point $E_{0}$ with the initial transfer $T_{0}$ (which could be zero) an increase of 
the transfer from $T_{0}$ to $T_{1}$ shifts the $R$-curve down to $R_{\mathrm{u}}\left(M ; T_{1}\right)$ if aid is non-tied and results in equilibrium $E_{1}$, as analyzed in Section 3. Similarly, an increase in the transfer from $T_{0}$ to $T_{1}$ if aid is tied to manufactures in general but the tying restriction (26) is not effective also results in a downward shift of the $R$-curve to $R_{\mathrm{tm}}\left(M ; T_{1}\right)=R_{\mathrm{u}}\left(M ; T_{1}\right)$ and therefore also results in equilibrium $E_{1}$. Suppose that at $T_{1}$ the tying-to-manufactures restriction (26) becomes just binding, i.e. $\alpha_{\mathrm{B}}\left(I_{\mathrm{B}}\right.$ $\left.+T_{1}\right)=T_{1}$. A further increase of the transfer from $T_{1}$ to $T_{2}$ results in a further downward shift of the $R$-curve to $R_{\mathrm{u}}\left(M ; T_{2}\right)$ and equilibrium $E_{2}^{\prime}$ if aid is non-tied. In contrast, a further increase of the transfer from $T_{1}$ to $T_{2}$ leads to an upward shift to $R_{\mathrm{tm}}\left(M ; T_{2}\right)>R_{\mathrm{tm}}\left(M ; T_{1}\right)=R_{\mathrm{u}}\left(M ; T_{1}\right)>R_{\mathrm{u}}\left(M ; T_{2}\right)$ and equilibrium $E_{2}$ if aid is tied to food. Therefore we can conclude that, independently of the size of the transfer, aid tied to manufactures in general leads to opposite effects on the price of manufactures, the number of varieties produced, etc. than non-tied aid provided the tying restriction (26) is effective. To put it differently, tying aid to manufactures in general leads to a 'reversal effect'.

For the reasons discussed in Section 4.1 we evaluate derivatives at the same initial equilibrium, in which the tying-of-aid restriction (26) is just binding. Differentiation leads to $^{21}$

$$
\left.\hat{r}\right|_{\mathrm{tm}}=\left.\hat{p}\right|_{\mathrm{tm}}=\left.\sigma \hat{n}\right|_{\mathrm{tm}}=\left.\sigma \hat{M}\right|_{\mathrm{tm}}=-\left[\left(1-\alpha_{\mathrm{A}}\right) /\left(\alpha_{\mathrm{A}}-\alpha_{\mathrm{B}}\right)\right] \hat{r}>0>\hat{r} .
$$

From which it is immediately clear that the price and variety changes are positive rather than negative if aid is tied to manufactures in general instead of non-tied. This follows from the fact that the recipient is forced, through the tying of aid, to spend the increase of the transfer exclusively on the consumption of manufactures, rather than just the fraction $\alpha_{\mathrm{A}}$, which is what the donor would have spent on manufactures from that part of its income. This, then, leads to an increase in the demand for manufactures and hence an increase in its price and the quantity supplied through an increase in the number of varieties. The welfare changes are given by

$$
\begin{aligned}
& \left.\hat{\vartheta}_{\mathrm{A}}\right|_{\mathrm{tm}}=\left.\left(\omega_{\mathrm{A}}-\alpha_{\mathrm{A}}\right) \hat{p}\right|_{\mathrm{tm}}+\left.\phi_{\mathrm{A}} \hat{n}\right|_{\mathrm{tm}}-\left(1 / \eta_{\mathrm{A}}\right) \hat{T}>\hat{\vartheta}_{\mathrm{A}}, \\
& \left.\hat{\vartheta}_{\mathrm{B}}\right|_{\mathrm{tm}}=\left.\left(\omega_{\mathrm{B}}-\alpha_{\mathrm{B}}\right) \hat{p}\right|_{\mathrm{tm}}+\left.\phi_{\mathrm{B}} \hat{n}\right|_{\mathrm{tm}}+\left(1 / \eta_{\mathrm{B}}\right) \hat{T} .
\end{aligned}
$$

The donor is now faced with a positive terms-of-trade effect and a positive love-of-variety effect, but a negative direct income effect. Its welfare decrease will be smaller than if aid is non-tied. Indeed, the donor may even gain through the tying of aid to manufactures if the love-of-variety effect dominates the direct income effect. The recipient, on the other hand, is confronted with two positive effects and one negative effect. As before, its direct income effect is positive because it receives the transfer. The terms-of-trade effect is now negative as the

\footnotetext{
${ }^{21}$ The $\left.\right|_{\text {tm }}$ sign indicates that aid is tied to manufactures in general.
} 
price of manufactured goods rises; an effect which may be potentially counterbalanced by the positive love-of-variety effect if the elasticity condition does not hold. The benefit of tying aid to manufactures is the increase in the number of varieties produced, a positive externality for all countries involved. Aid tied to manufactures will therefore lead to an outward shift of the utility possibility locus, rather than an inward shift (as would be the case with non-tied aid or aid tied to food).

Proposition 4. Under Assumption 1 aid tied to manufactures in general compared to non-tied aid induces

$i \quad$ a price increase for all manufactured goods,

ii an increase in the number of varieties in the manufactured goods industry,

iii a smaller welfare loss (or possibly a welfare gain) for the donor,

iv a smaller welfare gain for the recipient iff the elasticity condition holds.

It has become clear from Propositions 2-4 that some transfer paradoxes cannot be ruled out. In particular, if aid is non-tied or tied to food the recipient's welfare may fall (and hence everyone is worse off), while if aid is tied to manufactures the donor's welfare may rise (and hence everyone may gain). Simulations suggest that these paradoxes only occur for very small values of $\beta$ (close to 0.01 ), and hence very high values of $\phi_{k}\left(=\alpha_{k}(1-\beta) / \beta\right)$, and are largely independent of the other parameters in the model, see Brakman and van Marrewijk (1991b) for details. Low values of $b$ correspond to an elasticity of demand close to one, much lower than the lowest empirical estimate (5.8) found by Gasiorek et al. (1991). We therefore do not consider it very likely for transfer paradoxes to occur in practice.

\section{A fictitious restriction?}

The previous section discussed generic tied aid, i.e. aid tied to food in general or to manufactures in general. In reality, however, if aid is tied it is usually tied to a specific good produced in the donor country. For example, Japan gives aid to Indonesia provided the money is used to buy tractors in Japan. ${ }^{22}$ Without loss of generality we assume the specific good to be good $X_{1}$. Suppose, then, in the same vein as in the previous section, that the world is in an initial equilibrium in which country A gives non-tied aid to country $B$ and that this transfer is just large enough for country $B$ to pay for the purchase of manufacturing good $X_{1}$, which is imported from country A, i.e. $T=p\left[\alpha_{\mathrm{B}}\left(I_{\mathrm{B}}+T\right) / p n\right]$. One might be tempted to argue that the mere proclamation by country $A$ that henceforth aid is tied to the purchase of manufacturing good $X_{1}$ would not alter the equilibrium in the world

\footnotetext{
${ }^{22}$ The transfer is, of course, still given in terms of the numeraire, with Eq. (33) as tying restriction.
} 
economy since the restriction imposed is already fulfilled by the current equilibrium (and therefore appears to be a fictitious restriction). This reasoning would be wrong, however, as we will now explain.

The recipient solves the maximization problem subject to the budget constraint and the tying-of-aid constraint

$$
p_{1} X_{1}^{\mathbf{B}} \geq T \text {. }
$$

If the tying of aid constraint is binding expenditures on good $X_{1}$ are equal to the transfer and the remainder of the income is used to buy the other $(n-1)$ manufactured goods and food which leads to the following demand relations for the recipient:

$$
\begin{aligned}
X_{1}^{\mathrm{B}} & =T / p_{1}, \\
X_{i}^{\mathrm{B}} & =\alpha_{\mathrm{B}} I_{\mathrm{B}} / p(n-1), \quad i=2, \ldots, n, \\
F^{\mathrm{B}} & =\left(1-\alpha_{\mathrm{B}}\right) I_{\mathrm{B}} .
\end{aligned}
$$

The producer of good $X_{1}$ can take advantage of the restriction being imposed upon the consumers in the less developed country. If he could charge different prices in the two countries he could set the price in country $\mathbf{B}$ arbitrarily high and still receive revenue $T$ because demand for manufactured good $X_{1}$ in country B is now unit elastic (while a higher price means lower quantity demanded and hence lower cost). We assume, however, that consumer arbitrage between the two countries forces the producer of good $X_{1}$ to charge the same price in both countries. Let $\epsilon_{\mathrm{A}}\left(\epsilon_{\mathrm{B}}\right)$ be the elasticity of demand in country $\mathrm{A}(\mathrm{B})$, let $\epsilon$ be the overall elasticity of demand and let $\theta_{\mathrm{A}}$ be the share of sales in country $A$, i.e. $\theta_{\mathrm{A}}=X^{\mathrm{A}} /\left(X^{\mathrm{A}}+X^{\mathrm{B}}\right)$, then the following relation holds:

$$
\epsilon_{i}=\theta_{\mathrm{A}} \epsilon_{\mathrm{A}}+\left(1-\theta_{\mathrm{A}}\right) \epsilon_{\mathrm{B}} \quad i=1, \ldots, n,
$$

that is, the overall elasticity of demand is a weighted average of the elasticity of demand in the two countries. For all producers $i=2, \ldots, n$, we have $\epsilon_{\mathrm{A}}=1 /(1-$ $\beta)=\epsilon_{\mathrm{B}}$ and hence $\epsilon_{i}=1 /(1-\beta)=\epsilon$, say. ${ }^{23}$ For the producer of good 1 , however, $\epsilon_{\mathrm{A}}=1 /(1-\beta)>1=\epsilon_{\mathrm{B}}$ and hence $\epsilon_{1}<\epsilon$. Since all producers equate marginal revenue and marginal cost according to the rule

$$
p_{i}\left[1-1 / \epsilon_{i}\right]=r b
$$

this implies that the producer of good $X_{1}$ charges a higher price than his competitors which allows him to make a profit. As a result the sales of each competitor $i=2, \ldots, n$ at the old price will increase slightly, which leads to profits,

\footnotetext{
${ }^{23}$ The reader should not be tempted to deduce from Eq. (35) that the demand for manufactures $X_{i}$, $i>1$, is unit elastic because this equation already uses the fact that all prices $p_{i}, i>1$, are the same. An individual producer has no control over the other prices, indeed takes these as given, from which follows demand elasticity $1 /(1-\beta)$.
} 
which in turn causes an increase in the price and number of varieties produced.

Proposition 5. The imposition of an 'imaginary' constraint, tying aid to a specific manufactured good, causes

$i$ a price increase for all manufactured goods,

ii an increase in the number of varieties,

iii a higher price for the manufactured good to which aid is tied than for the other manufactured goods,

iv profits for the producer of the good to which aid is tied.

The 'fictitious' restriction has real effects because it affects the elasticity of demand for the 'privileged' producer. Obviously, the possibility for the 'privileged' producer to have positive profits if aid is tied to the production of its good explains both the envy of other producers, who will object to this practice, and the existence of lobby groups for certain producers in trying to acquire the 'privileged' status. Effectively, the tying of aid to a specific manufactured good in the donor country largely repatriates the transfer in terms of profits for this manufacturing good industry. Therefore, countries involved to a large extent in this type of tied aid practice appear much more generous than they really are.

\section{Differences in demand elasticity}

Naturally, under Assumption 1 a manufacturing firm, in the absence of tariffs, quotas or transport costs, will automatically charge the same price in both countries because the elasticity of demand is the same in both countries. Even if demand elasticities differ between countries a producer will be forced to charge the same price in both countries through consumer arbitrage if consumers in country A (B) can purchase goods in country B (A), as we assumed in Section 5. We will now briefly investigate the consequences of differences in demand elasticity between donor and recipient. For clarity in exposition we will use Assumption 2, but it is of course trivial to change the relation between $\beta_{\mathrm{A}}$ and $\beta_{\mathrm{B}} \cdot{ }^{24}$

\footnotetext{
${ }^{24}$ Empirical evidence does not support Assumption 2 (nor the alternative, i.e. demand is more elastic in less developed countries). Just restricting ourselves, for example, to the large developed countries (Germany, France, Italy, United Kingdom, United States and Japan) compared to the less developed countries (Rest of the World) in table 19 of Stalioner (1987) shows that 16 times demand is more elastic in the developed countries, while 14 times demand is more elastic in the less developed countries. One would therefore have to investigate the consequences of aid on a case by case basis.
} 
Assumption 2. The elasticity of demand is higher in the developed country than in the less developed country, i.e. $\beta_{A}>\beta_{B}$, while the share of income spent on manufactured goods is identical in both countries, i.e. $\alpha_{A}=\alpha_{B}=\alpha$.

Suppose, furthermore, that the producer of a manufactured good can take advantage of the different elasticities of demand in each market and can set different prices in different markets. This implies, from the marginal revenue equals marginal cost condition, that the price charged for manufactured goods will be higher in country $B$ than in country $A$.

$$
\begin{aligned}
& p_{\mathrm{A}} \beta_{\mathrm{A}}=r b, \\
& p_{\mathrm{B}} \beta_{\mathrm{B}}=r b .
\end{aligned}
$$

The zero-profit condition changes to

$$
p_{\mathrm{A}} X^{\mathrm{A}}+p_{\mathrm{B}} X^{\mathrm{B}}=r M / n
$$

where $X^{\mathrm{A}}\left(X^{\mathrm{B}}\right)$ is consumption in country $\mathrm{A}(\mathrm{B})$ given by

$$
\begin{aligned}
& X^{\mathrm{A}}=\alpha\left(I_{\mathrm{A}}-T\right) / p_{\mathrm{A}} n, \\
& X^{\mathrm{B}}=\alpha\left(I_{\mathrm{B}}+T\right) / p_{\mathrm{B}} n .
\end{aligned}
$$

Equilibrium in the food market gives

$$
I_{\mathrm{B}}+G(M)=(1-\alpha)\left[\left(I_{\mathrm{A}}-T\right)+\left(I_{\mathrm{B}}+T\right)\right]=(1-\alpha)\left(I_{\mathrm{A}}+I_{\mathrm{B}}\right)
$$

and is therefore independent of the size of the transfer. Equilibrium in the food market, using $I_{\mathrm{A}}=G(M)+r M$, reduces to

$$
\alpha\left(I_{\mathrm{B}}+G(M)\right)+(1-\alpha) G^{\prime}(M) M=0
$$

which determines the quantity of intermediates produced. This then sequentially gives $F, r, p_{\mathrm{A}}, p_{\mathrm{B}}$ and $I_{\mathrm{A}}$. Solving for the number of varieties we get

$$
n=\left(1-\beta_{\mathrm{B}}\right) M / a-\left(\beta_{\mathrm{A}}-\beta_{\mathrm{B}}\right)(\alpha / r a)\left(I_{\mathrm{A}}-T\right)
$$

from which it readily follows that an increase in the transfer leads to an increase in the number of varieties produced iff demand is more elastic in the donor country than in the recipient country $\left(\beta_{\mathrm{A}}>\beta_{\mathrm{B}}\right)$.

Proposition 6. Under Assumption 2 and price discrimination an increase in the transfer from country $A$ to country $B$

$i$ does not change the equilibrium prices of food and intermediates, nor the equilibrium production quantities of food and intermediates,

ii increases the number of varieties produced,

iii leads to a welfare gain for the recipient.

The results from Proposition 6 are intuitively straightforward to explain. Suppose that country A increases the transfer to country B. Since donor and 
recipient spend an equal proportion of this income on food consumption the equilibrium condition in the food market is not changed, hence the production level of food and intermediates is not affected by the transfer. This means that the price of intermediates, the income level $I_{\mathrm{A}}$ and the prices for manufactures charged in the different countries do not change. The only things that do change are the consumption levels in countries $A$ and $B$ and the number of varieties produced. Recall the spending levels of countries $\mathrm{A}$ and $\mathrm{B}$ on a representative manufactured good.

$$
\begin{aligned}
& X^{\mathrm{A}}=\alpha\left(I_{\mathrm{A}}-T\right) / p_{\mathrm{A}} n, \\
& X^{\mathrm{B}}=\alpha\left(I_{\mathrm{B}}+T\right) / p_{\mathrm{B}} n .
\end{aligned}
$$

Hence given the produced number of varieties $(n)$ an increase in the transfer $T$ will shift demand away from country A to country B where the price is higher (because demand is less elastic in country B). This will therefore increase revenues without increasing costs, which attracts new firms into the market, thereby reducing the quantity demanded for an individual producer at a given price level such that profits are again zero. Under these conditions, then, a transfer leads to an increase in the number of varieties produced and to an outward shift of the utility possibility locus. The donor is confronted with a negative income effect and a positive love-of-variety effect, while the recipient is confronted with a positive income effect and a positive love-of-variety effect (and therefore gains from an increase in the transfer).

What happens if the manufacturer cannot charge different prices in the two markets? Basically the same results still hold, because an increase in the transfer does not affect the food market equilibrium condition while demand has shifted to the country with a lower demand elasticity which therefore raises prices and the number of intermediates produced.

\section{Conclusions}

Kemp and Kojima (1985a) show the possibility of transfer paradoxes if aid is tied in a Walrasian stable, two-good, two-country framework. This result can be understood in terms of familiar results either by realizing that there are really three agents (the government) or that the tying itself represents a distortion. Schweinberger (1990) models aid in terms of 'forced choices' and shows that under tied aid the model is decomposable (the terms of trade are independent of the preferences of the recipient). We derive the same results while restricting ourselves, in contrast to the above contributions, to Spence-Dixit-Stiglitz preferences in a popular, non-Pareto-optimal trade model which also incorporates increasing returns to scale and imperfect competition. We have three basic new results. First, there are three, rather than two, welfare effects, i.e. in addition to the well-known 
terms-of-trade effect and direct income effect there is a love-of-variety effect which may potentially dominate the other two effects. This third welfare effect becomes less important if the elasticity of substitution for manufactured goods increases. Second, if the donor spends more on manufactures than the recipient (with equal demand elasticity): (i) the price of manufactures and the number of varieties decreases and the donor always loses if aid is non-tied, while the recipient gains if an elasticity condition is fulfilled; (ii) non-tied aid leads to an inward shift of the utility possibility locus; (iii) the results from (i) and (ii) are magnified if aid is tied to food and reversed if aid is tied to manufactures in general; (iv) welfare paradoxes are possible if the elasticity of demand is close to one, and (v) the imposition of tied aid with respect to a specific manufactured good increases the price of this good and enables the producer of that good to make a profit, thereby largely repatriating the transfer. Third, if the donor's demand is more elastic than the recipient's (with equal spending patterns) then an increase in aid does not change the terms of trade but increases both the number of varieties produced and the welfare level of the recipient (and leads to an outward shift of the utility possibility locus).

\section{Acknowledgements}

Part of this article was written while the second author was visiting professor at Cornell University. Financial assistance from the IDE-foundation and the Erasmus University Trust Fund is gratefully acknowledged. An earlier version was presented at the Seventh Annual Congress of the European Economic Association, Dublin 1992 and the Seventh Annual Congress of the European Association of Development Institutes, Berlin 1993. We would like to thank, without implicating, two anonymous referees, Filip Abraham, Andries Brandsma, John Chipman, Catrinus Jepma, Murray Kemp, Albert Schweinberger, Georg Tillmann and seminar participants at New York University, Purdue University, Erasmus University Rotterdam, the University of Groningen and the University of Leuven for useful remarks and suggestions.

\section{Appendix A}

This appendix shows that Eq. (16) in the text still holds if aid is tied to food if the tying is just effective, i.e. if $\left(1-\alpha_{\mathrm{B}}\right)\left(I_{\mathrm{B}}+T\right)=T$. The demand relations for country $B$ are

$$
\begin{aligned}
X_{i}^{\mathrm{B}} & =I_{\mathrm{B}} / p n, \quad i=1, \ldots, n, \\
F^{\mathrm{B}} & =T,
\end{aligned}
$$


which leads to the indirect utility function

$$
\vartheta_{\mathrm{B}}=\left(p^{-\alpha_{\mathrm{B}}}\right)\left(n^{\phi_{\mathrm{B}}}\right)\left(I_{\mathrm{B}}^{\alpha_{\mathrm{B}}}\right) T^{\left(1-\alpha_{\mathrm{B}}\right)}
$$

Differentiating (A.3) results in ( $I_{\mathrm{B}}$ is given)

$$
\begin{gathered}
\hat{\vartheta}_{\mathrm{B}}=-\alpha_{\mathrm{B}} \hat{p}+\phi_{\mathrm{B}} \hat{n}+\left(1-\alpha_{\mathrm{B}}\right)(\mathrm{d} T / T) \\
=-\alpha_{\mathrm{B}} \hat{p}+\phi_{\mathrm{B}} \hat{n}+\left(1-\alpha_{\mathrm{B}}\right)(r M / T)(\mathrm{d} T / r M) \\
=-\alpha_{\mathrm{B}} \hat{p}+\phi_{\mathrm{B}} \hat{n}+\left(1-\alpha_{\mathrm{B}}\right)\left[r M /\left(I_{\mathrm{B}}+T\right)\right]\left[\left(I_{\mathrm{B}}+T\right) / T\right] \hat{T} \\
=-\alpha_{\mathrm{B}} \hat{p}+\phi_{\mathrm{B}} \hat{n}+\left(1-\alpha_{\mathrm{B}}\right)\left(1 / \eta_{\mathrm{B}}\right)\left[\left(I_{\mathrm{B}}+T\right) / T\right] \hat{T} \\
=-\alpha_{\mathrm{B}} \hat{p}+\phi_{\mathrm{B}} \hat{n}+\left(1 / \eta_{\mathrm{B}}\right) \hat{T}
\end{gathered}
$$

because $\left(1-\alpha_{\mathrm{B}}\right)\left[\left(\mathrm{I}_{\mathrm{B}}+T\right) / T\right]=1$ if tying is just effective. Showing that Eq. (16) in the text still holds if aid is tied to manufactures in general if the tying is just effective is entirely analogous.

\section{References}

Abraham, F., 1991, Social protection and regional convergence in an EMU. Mimeo. (University of Leuven, Leuven).

Bhagwati, J.N., R.A. Brecher and T. Hatta, 1983, The generalized theory of transfers and welfare: Bilateral transfers in a multilateral world, The American Economic Review 73, 606-618.

Bhagwati, J.N., R.A. Brecher and T. Hatta, 1985, The generalized theory of transfers and welfare: Exogenous (policy-imposed) and endogenous (transfer-induced) distortions, The Quarterly Journal of Economics, Aug., 697-714.

Brakman, S. and C. van Marrewijk, 1991a, A note on endogenous transfers, Journal of Economics 54, 171-178.

Brakman, S. van C. van Marrewijk, 1991b, On the economics of tied aid, Research memorandum no. 444 (University of Groningen, Groningen).

Chichilnisky, G., 1980, Basic goods, the effects of commodity transfers and the international economic order, Journal of Development Economics 7, 505-519.

Chipman, J.S., 1966, A survey of the theory of international trade, Part III, Econometrica.

Choi, J.-Y. and S.H.E. Yu, 1987, Immiserizing transfers under variable returns to scale, Canadian Journal of Economics 20, 634-645.

Clague, C.K., 1991, Factor proportions, relative efficiency and developing countries' trade, Journal of Development Economics 35, 357-380.

Dixit, A.K. and V. Norman, 1980, Theory of international trade (Cambridge University Press, Cambridge).

Dixit, A.K. and J.E. Stiglitz, 1993, Monopolistic competition and optimum product diversity: Reply, American Economic Review 83, 302-304.

Ethier, W., 1982, National and international returns to scale in the modern theory of international trade, American Economic Review 72, 389-405.

Ethier, W. and H. Horn, 1984, A new look at economic integration, in: H. Kierzkowski, ed., Monopolistic competition and international trade (Clarendon Press, Oxford).

Gale, D., 1974, Exchange equilibrium and coalitions: An example, Journal of Mathematical Economics $1,63-66$. 
Gasiorek, M., A. Smith and A.J. Venables, 1991, Completing the internal market in the EC: Factor demands and comparative advantage, in: A.L. Winters and A.J. Venables, eds., European integration: Trade and industry (Cambridge University Press, Cambridge) 9-30.

Helpman, E., 1981, International trade in the presence of product differentiation, economies of scale and monopolistic competition, Journal of International Economics 11, 305-340.

Horn, H., 1984, Product diversity, trade and welfare, in: H. Kierzkowski, ed., Monopolistic competition and international trade (Clarendon Press, Oxford) 51-68.

Jepma, C.J., 1991, The tying of aid (OECD, Paris).

Jones, R.W. and J.P. Neary, 1984, The positive theory of international trade, in: R.W. Jones and P.B. Kenen, eds., Handbook of international economics, Vol. I (North-Holland, Amsterdam).

Kemp, M.C. and S. Kojima, 1985a, Tied aid and the paradoxes of donor-enrichment and recipient-impoverishment, International Economic Review 26, 721-729.

Kemp, M.C. and S. Kojima, 1985b, The welfare economics of foreign aid, in: G.R. Feiwel, ed., Issues in contemporary microeconomics and welfare (MacMillan, London).

Kemp, M.C. and S. Kojima, 1987, More on the welfare economics of foreign aid, Journal of the Japanese and International Economies 1, 97-109.

Kemp, M.C. and K. Shimomura, 1991, 'Trade' or 'aid'?, in: A. Takayama, M. Ohyama and H. Ohta, eds., Trade, policy, and international adjustments (Academic Press, London).

Krugman, P.R., 1979, Increasing returns, monopolistic competition and international trade, Journal of International Economics 9, 469-479.

Krugman, P.R., 1990, Rethinking international trade, (Cambridge University Press, Cambridge).

Lancaster, K., 1980, Intra-industry trade under perfect monopolistic competition and international trade, Journal of International Economics 10, 151-175.

Markusen, J.R., 1986, Explaining the volume of trade: An eclectic approach, American Economic Review 76, 1002-1011.

Ohyama, M., 1974, Tariffs and the transfer problem, Keio Economic Studies 11, 29-45.

Schweinberger, A.G., 1990, On the welfare effects of tied aid, International Economic Review 31, $457-462$.

Stalioner, A., 1987, Estimation and simulation of international trade linkages in the QUEST model, European Economy 31.

Tirole, J., 1988, The theory of industrial organization (Harvard University Press, Cambridge, MA).

van Daal, J. and A.H.Q.M. Merkies, 1984, Aggregation in economic research (Reidel Publishing Co., Dordrecht). 